\title{
User's Satisfaction of Kuwait E-Government Portal: Organization of Information in Particular
}

\author{
Huda R. Farhan and Mark Sanderson \\ Department of Information Studies University of Sheffield, UK \\ Sheffield, UK \\ H. farhan@shef.ac.uk, m.sanderson@shef.ac.uk
}

\begin{abstract}
Assessing the success of an information system might help in locating weak and strong points of the system leading to the improvement of system under assessment. A popular system evaluation construct is user's satisfaction. Different measuring instruments were developed to assess this construct at the organization environment. In addition to the traditional instruments that were develop to assess information system success, new instruments need to be adapted that can cope with the internet context. This paper presents a measuring instrument that was developed to evaluate Kuwait e-government user's satisfaction while seeking information via Kuwait e-government portal. The instrument was based on several satisfaction factors. The application of this instrument indicated that the suggested factors predict the overall user satisfaction.
\end{abstract}

Keywords: User's satisfaction, e-government portals, evaluation of information systems, satisfaction factors.

\section{Introduction}

Consulting e-government portals to fulfill information needs was considered as an information seeking process [21]. In order to fulfil information needs related to government facilities and services, citizens might consult e-government portals instead of visiting the government institutions. The e-government portal's ability to satisfy citizens' information needs will affect how users perceive, revisit and use the portal and determine their degree of satisfaction. Thereby, measuring citizens' satisfaction will help in determining the success or failure of the portal from a user perspective and lead to the improvement of the portal, increase usage and loyalty [10].

Citizens' satisfaction as information seekers in an e-government context was not the focus of the literature in the field. Most of the studies were focusing on either the technical design of e-government portals [14]; [3], service quality [16];[18] or proposed evaluation methods [21]. Thereby, a need was identified to explore the success of an egovernment portal from a user's perspective. The Kuwait e-government portal was chosen for this purpose. Knowing that it is a newly lunched portal and never been evaluated for success based on user's satisfaction. To measure users' satisfaction while using Kuwait e-government portal, a measuring instrument was developed based on Bailey and Pearson's users' information satisfaction instrument. The developed 
instrument was designed based on several satisfaction factors that were introduced in previous literature. In addition to the subjects' overall satisfaction the measuring instrument is expected to assess a particular dimension of users' satisfaction which is the organization of information. Another aim of this study was to measure the ability of the suggested satisfaction factors to predict the overall satisfaction.

The measuring instrument was applied surveying 229 Kuwaitis. In this paper user's satisfaction as an evaluation measure was discussed, followed by related studies. After that, the design of the measuring instrument was introduced along with the data collection and methodology. Finally, a discussion of the findings was provided, followed by the conclusion.

\section{Can User's Satisfaction Work as an Evaluation Measure?}

[2] Defined user satisfaction in a certain situation as "the sum of one's feelings or attitudes toward a variety of factors affecting that situation". Measuring user's satisfaction of information systems would facilitate detecting weaknesses and strength of a system from a users' point of view [12]. In addition, users' satisfaction "measures how users view their information system rather than the technical quality of the system"[15]. [17] Assumed the lack of theoretical assessment of user satisfaction as a measure of information system effectiveness, concentrating only on user's satisfaction rather than exploring attitude in its broad meaning. [17]Questioned the relation between user satisfaction and information system effectiveness in the organization environment where the system use is mandatory. In organization context -where most of the user's satisfaction studies were conducted- users' satisfaction was perceived as " $a$ reflection of the context to which the information needs of manager have been met" [13]. Different measuring instruments were developed to measure UIS. The most common used measures are: "Bailey and Pearson, 1983; Baroudi and Orlikowski, 1988; Doll and Torkzadeh, 1988; Goodhue, 1988; Ives, et al., 1983; Jenkins and Ricketts, 1979, Doll et al., 1994).

[2] Developed a measuring instrument consisting of 39 factors to measure satisfaction. [8] Developed an instrument to measure the end user satisfaction with a specific application. The instrument consisted of five factors; content, accuracy, format, ease of use, time line. The factors measured via 12 items. The instrument was tested for validity and reliability. Asking 618 end users distributed at 44 different firms to fill out the questionnaire supported the generalizeability of the instrument. The instrument was found to be able to measure end user satisfaction of specific application, compare between applications and general satisfaction. [19] Believed that Jenkins and Ricketts 1979 instrument was "one of the few (if not the only) approaches that develops an instrument to measure user satisfaction that is well grounded in a widely accepted theoretical model"

[17] emphasized the need for an argument to relate user satisfaction and system use and system effectiveness. In addition, [17] called for studying the reverse direction of influence relation between attitude and behavior (the effect of behavior on attitude). [17] Believed that "user satisfaction instruments are currently employed to assess (relative) user dissatisfaction, to diagnose possible causes for dissatisfaction, and to suggest corrective action" 
[15] Investigated a number of users' satisfaction instruments to test their reliability as information system measures. [15] Investigation was based on four criterion; empirically derived measure, with adequate empirical support, which covers both the information system product and general system services, and provides multiple indicators. In this study it was found that Pearson's measure (1983) as having more potential as a UIS measure, which leads [15] to further investigate Pearson's measure (1983) to test its reliability and validity. Testing the measure on 800 managers with $25 \%$ response rate, [15] concluded that the measure is valid and can be considered as a step towards the establishment of standard measures of UIS, and suggesting further testing to validate the measure. [15] Modified the measure to make it shorter to meet general evaluation process.

[12] investigated the test and retest reliability of the detailed UIS measure - Bailey and Pearson's instrument (1983) that was refined and abbreviated by [1]. The summary part of the instrument was modified to represent each factor individually instead of having one global summary question owing to the heterogeneity of the instrument factors. Three groups of MBA students were recruited to answer the questionnaire. One group was exposed to system failure materials; the second group was exposed to system success materials, where the third group answered the questionnaire without prior preparation. The findings indicated that the instrument "lack test and retest reliability". Also, it was noticed that the summary questions were more reliable than the detailed questions. The researcher recommended further testing and retesting of the user's satisfaction detailed measure.

Using the confirmatory factor analysis, [9] tested the validity and reliability of Doll and Torkzadeh's end user computer satisfaction measuring instrument [8]. Applying the instrument on 409 computer end users affiliated with 18 organizations two of them government agencies - which support the generalizability of the results -, the researchers confirmed the validity and reliability of the instrument. Also, the findings of the study indicated that the instrument "explains and measures the users satisfaction construct", hence, can work as a standardized instrument to measure user's satisfaction with specific computer applications.

User satisfaction has been tested for reliability as a measure to evaluate information systems' success or failure. [13] Conducted a study to validate the use of user satisfaction and system usage as two measures of information systems success. A modified questionnaire (based on Doll and Torkzaddah) was deployed to investigate the relation between both measures and performance. The questionnaire addresses 5 dimensions of user's satisfaction: satisfaction with the content, accuracy, format, time line, ease of use. The findings of this study indicated that user's satisfaction is a reliable measure of information system success. Also, the study showed that satisfied users are more likely to use the system frequently. Regardless of researchers' different attitudes towards deploying user's satisfaction as a measure of information system success, [7] stated that "user information satisfaction continues to be the most commonly used and developed success measure".

\section{Related Studies}

In system management literature, several models had been developed to measure information system success in an organizational context (e.g. [7]; [11]). It was noticed 
that a common aspect to information system success models was the inclusions of user's satisfaction as a success construct whether to measure overall success or particular aspect of success.

User's satisfaction interacting with an electronic medical record system was evaluated by [20]. The evaluation instrument was especially designed for this study covering four satisfaction dimensions; overall user reactions, screen design and layout, terms and system information, learning and system capabilities. Seventy five physicians participated in the survey. The findings indicated that satisfaction was higher with screen design and layout more than system capabilities. The researcher recommended the use of terms preferred by physicians rather than terms chosen by the system developers.

Just like other research fields, research focussing on information system success was influenced by the existence of the internet. The impact of the internet on user satisfaction research can be understood from the call to redesign user satisfaction measuring instruments to meet the internet environment. Hence, new users' information satisfaction instruments were developed especially to measure users' information satisfaction in the internet context based on the assumption that internet environment differ from the organization environment in terms of usage and type of users [6]. In the internet environment, [4] evaluated Australian academics' satisfaction of the information seeking experience on the internet, and the relation between information seeking satisfaction and previous training, success expectation, and frequency of internet usage. Using the magnitude estimate method as well as questionnaire and structured interviews, 37 randomly selected Australian academics were recruited as subjects to report their satisfaction regarding information seeking experiences. [4] Didn't find any significant effect between information search previous training, frequency of internet usage and users' level of satisfaction. A moderate positive relation between information seeking satisfaction and success expectations was noticed, although this finding needed further investigation owing to the fact that subjects were asked to report success expectation after the completion of the information seeking process. Hence, the success expectation could be affected by the information seeking experience results. Finally, [4] research indicated that Australian academics have high expectation of information seeking in the internet and they were highly satisfied.

[6] Modified Goodhue's model to meet the requirements of the web environment to evaluate user's information satisfaction outside an organizational context. The model consisted of six concepts in addition to the Goodhue concepts that were seen as appropriate for the web environment. [6] Emphasized the importance of considering web users in developing web information system at the success of the system. The focus of the model wasn't only users' satisfaction instead two other dimensions were addressed; web usage and individual performance. The reliability of the instrument was low indicating the need for further improvement of the instrument.

\section{Methodology}

A user centric study was conducted to assess how citizens' are satisfied with their information seeking experience at the Kuwait e-government portal. The study was expected to explore the difficulties related to information classification and descriptive terms citizens encounter while retrieving government information. Our study was 
not concerned with information seeking behaviour. Instead our study focused on $\mathrm{Ku}$ wait e-government portal's ability to organize information in a way that adhered to citizens' information needs and information seeking preferences. In addition, the study did not focus on the well known measure of information retrieval systems (recall and precision), instead it focused on the users' perception of the success of the information retrieval system based on predefined satisfaction factors. A quantitative method was deployed to collect data for the purpose of this study. This study evolved based on investigating the following aims;

1. To assess how satisfied users are with their information seeking experience at the Kuwait e-government portal.

2. To investigate the effect of the methods used to organize information on the users' decision to revisit Kuwait e-government portal.

3. To develop a theoretically justifiable and empirically tested user satisfaction measuring instrument.

4. To explore the ability of the suggested satisfaction factors to predict user's overall satisfaction.

In order to meet the previous mentioned aims the following questions will be answered:

- What is the degree of citizen's information satisfaction regarding finding needed information in Kuwait e-government portal?

- To what extent can the suggested satisfaction factor reflect user's overall satisfaction?

Using [2] abbreviated user's satisfaction instrument as a starting point, a questionnaire was designed to collect data. Believing that user satisfaction is " $a b i$ dimensional attitude affected by a variety of factors" [2], the developed instrument consisted of seven factors with more than 3 indicators each. A summery section was included summarizing users' overall satisfaction. The questionnaire was detailed to assess particular dimension of satisfaction which was the organization of information. According to [12] "User satisfaction is a state at a given point in time (rather than a lasting trait) and more easily influenced by experience". Hence, the questionnaire was intended to address user's satisfaction of information seeking for information related to multiple real life events. This decision was made to eliminate the expected bias that may occur from a single failure incident. Seven factors of [2] were the base for our questionnaire; currency, understanding of the system, expectation as well as repeated visit [7] and recommendation (we believe that a user will recommend a system to his network if he is satisfied with this system), organization of information and ease of use [8]. Whenever applicable, relevant questions were adapted from previously tested and validated user's satisfaction measuring instruments and added to our instrument. In addition to addressing the satisfaction factors the questionnaire included several questions addressing users' computer skills, access to internet and hearing of the portal. The inclusion of these questions was to eliminate the effect of these factors on users' satisfaction. Hence, assure the assessment of the intended factors only. The questionnaire was piloted prior to the actual application to test reliability, design and language suitability to the participants. Changes and modifications were applied whenever needed based on the pilot test. 
Six hundred questionnaires were distributed at the main public libraries in Kuwait. The response rate was $55.1 \%$ representing 331 responses. Around 104 questionnaires were labeled as invalid and were not used. The excluded questionnaires suffer from missing information, contradicted answers that shows the participants answers were haphazard and not based on reading the questionnaire. The valid responses were 229 entered and manipulated using SPSS.

\section{Findings and Discussion}

The purpose of this evaluation was to investigate how satisfied users are of the information seeking experience at Kuwait e-government portal. The majority of subjects indicated that they can access computer with internet connection easily. Also, the majority of subjects believed that they have computer and internet skills that allowed them to search the internet and bookmark and describe documents they find. Therefore, Computer skills and computer and internet access were excluded as factors that affect usage and satisfaction. Also, Knowledge of the portal was excluded as a factor that might affect the portal usage and satisfaction. This decision was made based on the subjects responses indicating that they have heard about the portal.

Although technical issues such as pages slow downloads and dead links were not the focus of this study, it was noticed that technical issues do affect the usage of the portal. Around $68.2 \%$ of the respondents believed that technical issues they faced when using the portal prevented them from wanting to revisit the portal. Thereby, all conclusions derived from this study took into considerations the effect of the technical issues on user's satisfaction.

1- Understanding of the System

To explore subjects' understanding of Kuwait e-government portal, subjects were asked if they knew the goal of the portal as well as the type of information and services available at the portal. In addition, subjects were asked if they knew how to use the portal in their everyday life. The majority of subjects expressed a good understanding of the system. Around $97.6 \%$ understood the goal of the portal, and $87.1 \%$ knew the type of information and services available at the portal. Also, $92.9 \%$ knew how to make use of the portal in their everyday life. Furthermore, it was noticed that $79.6 \%$ of the subjects that expressed a good understanding of the portal indicated a high level of overall satisfaction with the information seeking experience using the system. The indication of this observation supported the assumption that understanding the system might be used to predict the overall satisfaction.

\section{2- Ease of Use}

Knowing that "the basic premise behind ease of use is designing a website that builds on the user's perspective" [5]. Subjects were asked if they found the portal easy to use when performing an information seeking process. More than $80 \%$ of subjects believed that the portal was easy to use. Around $90.6 \%$ consulted the portal when they didn't know where to search. Also, $83.5 \%$ found information in the portal more than other information resources. Finally, subjects who believed that using the portal helped them avoid going to the government institution building were around $80 \%$. As for the possibility of ease of use to act as a satisfaction factor, $80.5 \%$ of subjects who believed in the ease of use of the portal expressed a high level of overall satisfaction. 
Hence, supporting the assumption that ease of use can be used to predict the overall satisfaction.

\section{3- Currency of Information}

Subjects were asked to show their opinion about the currency of information available at the portal. Around $87 \%$ believed information available at the portal were current meeting their information needs. Also, $85 \%$ of subjects who believed information available at the portal was current also showed a high level of satisfaction. Hence, subjects' opinion about the currency of information can be used to anticipate the overall satisfaction.

\section{4- Repeated Visit}

To investigate the interval of visiting, the portal subjects were asked to state their frequency of visits on a five point scale. Subjects visiting the portal daily or once a week were considered as frequent users. Subjects that visited the portal less than that were considered less frequent users. A small number of subjects $20.0 \%$ considered themselves as more frequent users visiting the portal from daily to once a week. Although, $88 \%$ of subjects who considered themselves as frequent users expressed a high level of satisfaction, it was noticed that the majority of satisfied subjects $72.05 \%$ considered themselves as less frequent users. Therefore, repeated visit don't necessarily reflect the level of overall satisfaction. This finding goes in line with previous literature in both obligatory system usage and optional system usage. [4] No significant relationship between subject level of satisfaction and frequency of internet usage was found.

\section{5- Recommendation}

Believing that users recommend information channels that satisfy their information needs conveniently, and attempting to measure recommendation as a satisfaction factor, subjects were asked to recommend an information channel to other people based on two incidents; traffic violations and fines related to car insurance. The $\mathrm{Ku}-$ wait e-gov portal came as the second preferable information channel for the incidents discussed. However, the number of subjects recommending the portal was low. Most subjects $(50 \%)$ recommended a relevant ministry web site. Also, from the findings it was noticed that recommendation might reflect the overall satisfaction, around $84.9 \%$ of subjects that recommended the portal for both incidents investigated also, expressed a high level of satisfaction. The recommendation section of the questionnaire revealed a different preference pattern. The highest recommended information channel was the government institution web site followed by the e-government portal. This finding questions the appropriateness of considering recommendation as a user's satisfaction factor.

\section{6- Expectation}

The number of subjects that recommended the portal was low. However, Most of subjects $(96.9 \%)$ that recommended the portal had good expectation about the information seeking experience using the portal. The number of subjects with high expectations of the portal being of use to others for traffic violation and car insurance incidents were highly satisfied at the same time, respectively $82.8 \%$ and $60 \%$. This indicates that user expectation predicts overall satisfaction. [4] Findings indicated a moderate significant positive relationship between subject's expectation and the level of satisfaction. 


\section{8- Organization of Information}

Amongst the difficulties that [5] identified with users searching the internet for health information are; information overload and disorganization of information in addition to the need to know jargon and technical terms. Assessing how subjects perceived the way information was organized at the portal was another factor of satisfaction explored in this study. Subjects were asked about the effect of the way information was organized at the portal on their decision to revisit the portal. Also, subjects were asked whether they found the descriptive terms available at the portal easy to understand or ambiguous. 76.5 $\%$ of subjects believed information organization on the portal didn't affect their decision to revisit the portal. Most of subjects (78.4\%) believed that terms were clear. As for the relation between user's opinion about the way information was organized and the overall satisfaction, it was noticed that subjects with positive opinions expressed a high level of overall satisfaction. This finding suggested the possibility to consider organization of information as factor that might predict the overall satisfaction.

\section{Conclusion}

Although the number of subjects that actually used the portal in comparison to the subjects who heard of the portal was low (37.1\%), the majority of those subjects expressed a high level of overall satisfaction with the portal. The findings raised a need to locate effective methods to motivate users to consult the Kuwait e-government portal. In addition to assessing user's satisfaction with the information seeking experience using the Kuwait e-government portal, the data were analyzed to investigate the possibility of the suggested satisfaction factors to predict the overall satisfaction. The findings revealed the possibility of six factors to predict the overall satisfaction. These factors were; understanding of the system, ease of use, currency of information, recommendation and expectation and organization of information. The only factor that failed to reflect the overall satisfaction was repeated visit. This finding indicates the ability of the developed measuring instrument to measure user's satisfaction. Some modifications need to be applied to the instrument though. These modifications related to the factors that failed to predict the overall satisfaction.

Being part of an ongoing research, this study will be followed by a user's centric study. An exploratory lab controlled study will be conducted. Cross users comparative system success assessment will be performed. In this study, the focus will be on the method used to organize information at the portal in particular. Users will be introduced to two system interfaces. One interface with a previously generated folksonomy by end users and the other interface will be the original portal interface without folksonomy. The success of the portal will be based on comparing user's satisfaction utilizing the developed and modified measuring instrument

\section{References}

1. Baroudi, J.J., Olson, M.H., et al.: An Empirical Study of the Impact of User Involvement on System Usage and Information Satisfaction. Communication of the ACM 29(3), 232238 (1986)

2. Baily, J.E., Pearson, S.W.: Development of a Tool for Measuring and Analyzing Computer User Satisfaction. Management Science 29(5), 530-545 (1983) 
3. Becker, S.A.: E-Government Visual Accessibility for Older Adult Users. Social Science Computer Review 22(1), 11-23 (2004)

4. Bruce, H.: User Satisfaction with Information Seeking on the Internet. Journal of the American Society for Information Science 49(6), 541-556 (1998)

5. Cline, R.J.W., Haynes, K.M.: Consumer Health Information Seeking on the Internet: the State of the Art. Health Education Research 16(6), 671-692 (2001)

6. D'Ambra, J., Rice, R.E.: Emerging Factors in User Evaluation of the World Wide Web. Information and Management 38, 373-384 (2001)

7. Delone, W.H., Mclean, E.R.: The Delone and Mclean Model of Information System Success: A Ten- Year Update. Journal of Management Information Systems 19(4), 9-30 (2003)

8. Doll, W.J., Torkzadeh, G.: The Measurement of End -User Computing Satisfaction. MIS Quarterly 12(2), 259-274 (1988)

9. Doll, W.J., Torkzadeh, G.: A Confirmatory Factor Analysis of the End-User Computing Satisfaction Instrument. MIS Quarterly 18(4), 453-461 (1994)

10. Freed, L.: American Customer Satisfaction Index: E-Government satisfaction Index (2005), http://www.fcg.gov/documents/12-2007.pdf (retrieved June 16, 2008)

11. Gable, G.G., Sedera, D., et al.: Enterprise Systems Success: A measurement Model. In: Twenty-Fourth International Conference on Information Systerms, Seattle, USA (2003)

12. Galletta, D.F., Lederer, A.L.: Some cautions on the measurement of user information satisfaction. Decision Science 20, 419-438 (1989)

13. Gelderman, M.: The relation between user satisfaction, usage of information systems and performance. Information and Management 34, 11-18 (1998)

14. Ho, A.T.-K.: Reinventing Local Governments and the E-Government Initiative. Public Administration Review 62(4), 434-444 (2002)

15. Ives, B., Olson, M.H., et al.: The measurement of user information satisfaction. Communication of the ACM 26(10), 785-793 (1983)

16. Marcella, R., Baxter, G., et al.: The effectiveness of parliamentry information services in the United Kingdom. Government Information Quarterly 20(1), 29-46 (2003)

17. Melone, N.P.: Atheoretical assessment of the user satisfaction construct in information systems research. Management Science 36(1), 76-91 (1990)

18. Parent, M., Vandebeek, C.A., et al.: Building Citizen Trust Through E-government. Government Information Quarterly 4(22), 4720-4736 (2005)

19. Srinivasan, A.: Alternative measures of system effectiveness: associations and implications. MIS Quarterly 9(3), 243-253 (1985)

20. Sittig, D.F., Kuperman, G.J., et al.: Evaluating physician satisfaction regarding user interactions with an electronic medical record system. In: Proc. AMIA Symp., pp. 400-404 (1999)

21. Wang, L., Bretschneider, S., et al.: Evaluating Web-Based E-Government Services with a Citizen-Centric Approach. In: 38th Annual Hawaii International Conference on System Sciences (HICSS 2005)-Track 5, Hawaii, vol. 5. IEEE Computer Society, Los Alamitos (2005) 